\title{
Convergence or divergence of educational disparities in mortality and morbidity? The evolution of life expectancy and health expectancy by educational attainment in Austria in 1981-2006
}

\section{Johannes Klotz*}

\begin{abstract}
The continuous increase in life expectancy in developed countries is typically associated with an increase in the number of years in good health, whereas the number of years in bad health rather stagnates. At present relatively little is known about trends in educational disparities in mortality and particularly morbidity. By combining life tables from census follow-up with cross-sectional survey data on self-perceived health, we are able to estimate life expectancy as well as health expectancy differences between three educational groups in Austria in 1981-2006. All educational groups have substantially gained length and quality of life (both absolute and relative) during the last decades. Between medium and low educated females, we observe a significant decrease in the life expectancy difference, but a significant increase in the health expectancy difference. No significant changes in educational differences are found among males. The educational expansion of the population has shifted a large proportion of the population to lower-risk groups.
\end{abstract}

\section{Introduction}

\subsection{Persistent increase of length and quality of life in Austria}

Like many other countries, Austria has seen a large and more or less continuous increase in life expectancy for almost 150 years: Whereas in 1868/71 life expectancy at birth was 33 years for males and 36 years for females, today (2008) it is 78 years for males and 83 years for females; an increase of almost 50 years. Since 1950 the figures have increased by about 15 years (Figure 1), which, until

\footnotetext{
* Johannes Klotz, Population Statistics: Analysis and Projections, Statistics Austria, Guglgasse 13, 1110 Vienna, Austria. Email: Johannes.klotz@statistik.gv.at
} 
the 1960 s, was mainly caused by reductions in infant and child mortality rates through better prevention and treatment of infectious diseases. Since the 1970s, however, also mortality rates at older adult ages have declined considerably-a fact that was mainly caused by decreasing mortality rates with regard to chronic illnesses, particularly circulatory diseases (the "cardiovascular revolution", as quoted by Vallin and Mesle 2004). Today, reductions in old-age mortality rates are the main reason for the increasing life expectancy in Austria (Figure 2) as well as other western European countries.

\section{Figure 1:}

Period life expectancy at birth. Austria in 1950-2008

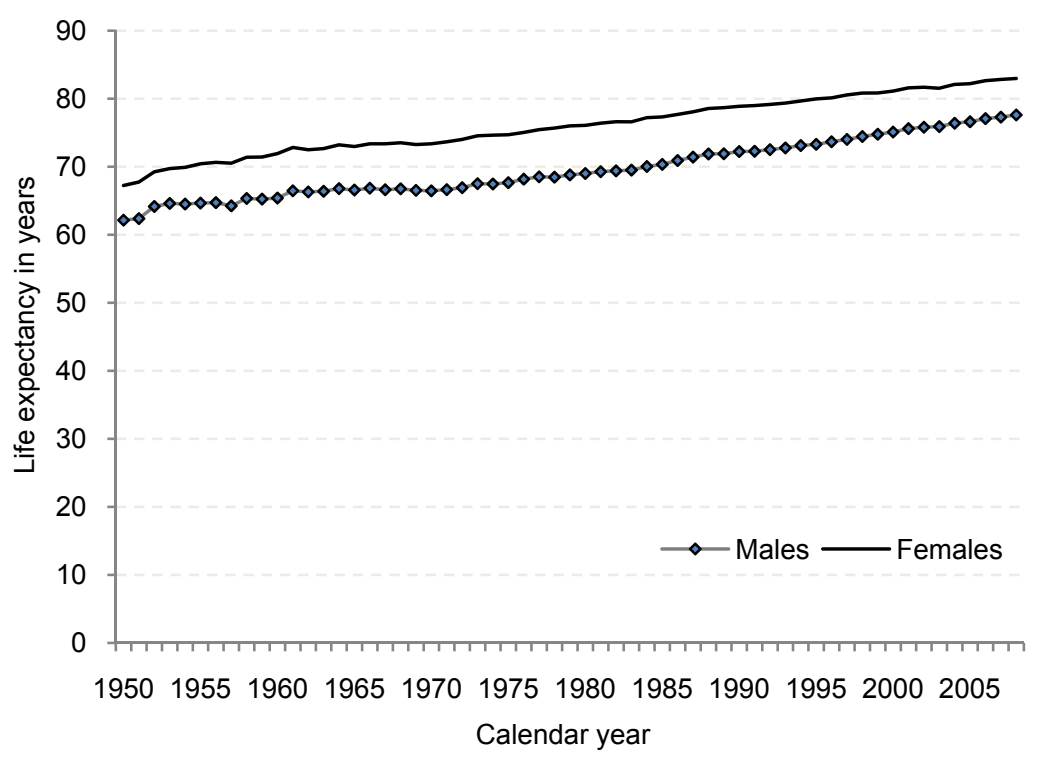

Source: Statistics Austria 
Figure 2:

Contribution of age-specific mortality reductions to increases in life expectancy at birth. Austria in 1950-2008

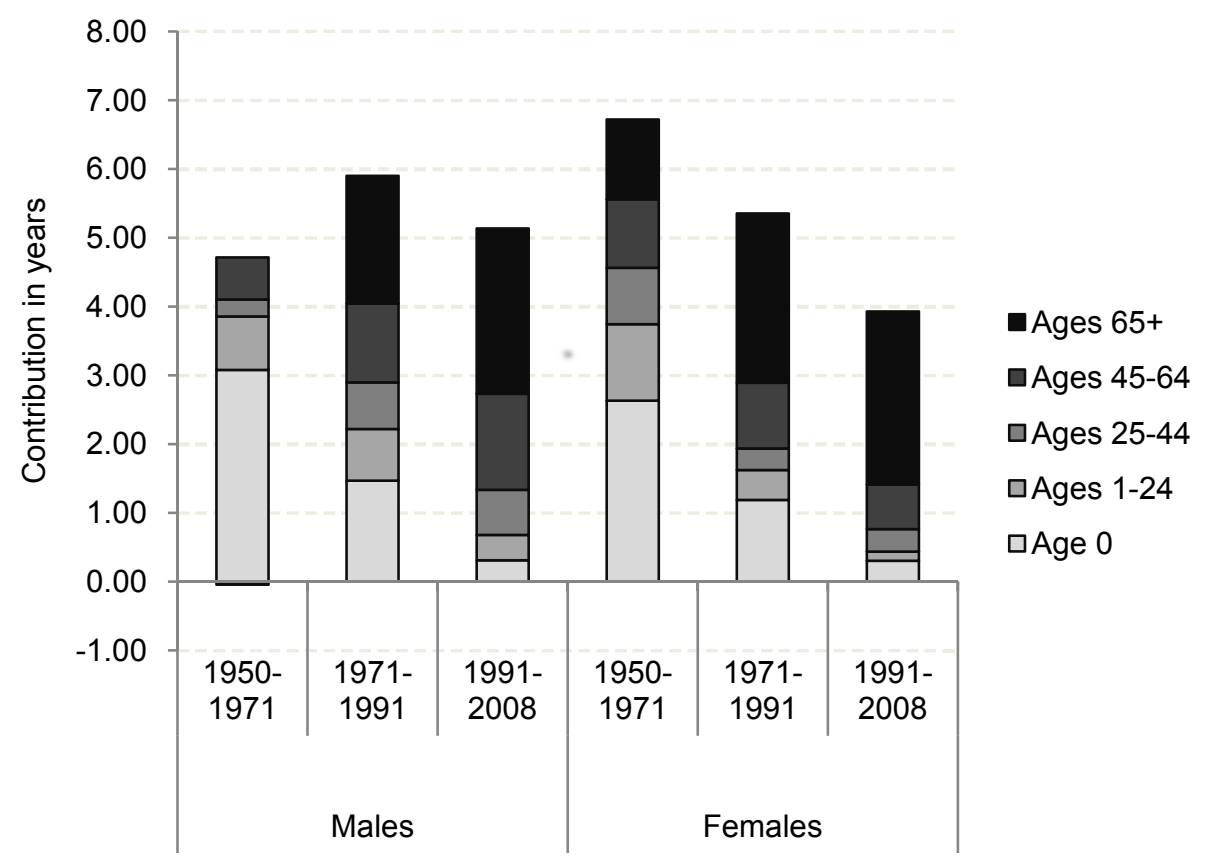

Source: Statistics Austria

The fact that the annual gains in life expectancy are increasingly caused by declining mortality rates at older adult ages has induced intensive discussion about the epidemiologic implications of the post-1970 gains in life expectancy in developed countries. Some researchers doubted that in this case the traditional interpretations of life expectancy increases as indicators of 'healthier populations' were still applicable (for a detailed reference see Nusselder 2003). However, the majority of the statistical data for developed countries indicates substantial improvements in population health during the last decades. Comparing Austrian survey data of 1981 with 2006, it turns out that the age-specific proportion of the population self-rating its health as very good or good has increased for both sexes in practically all 5-year age groups between the ages of 25-84 years (Figure 3). Moreover, the increase in self-rated very good or good health was most pronounced among the elderly. 
Figure 3:

Age-specific proportion (\%) of the Austrian population in self-perceived (very) good health, 1981 vs. 2006
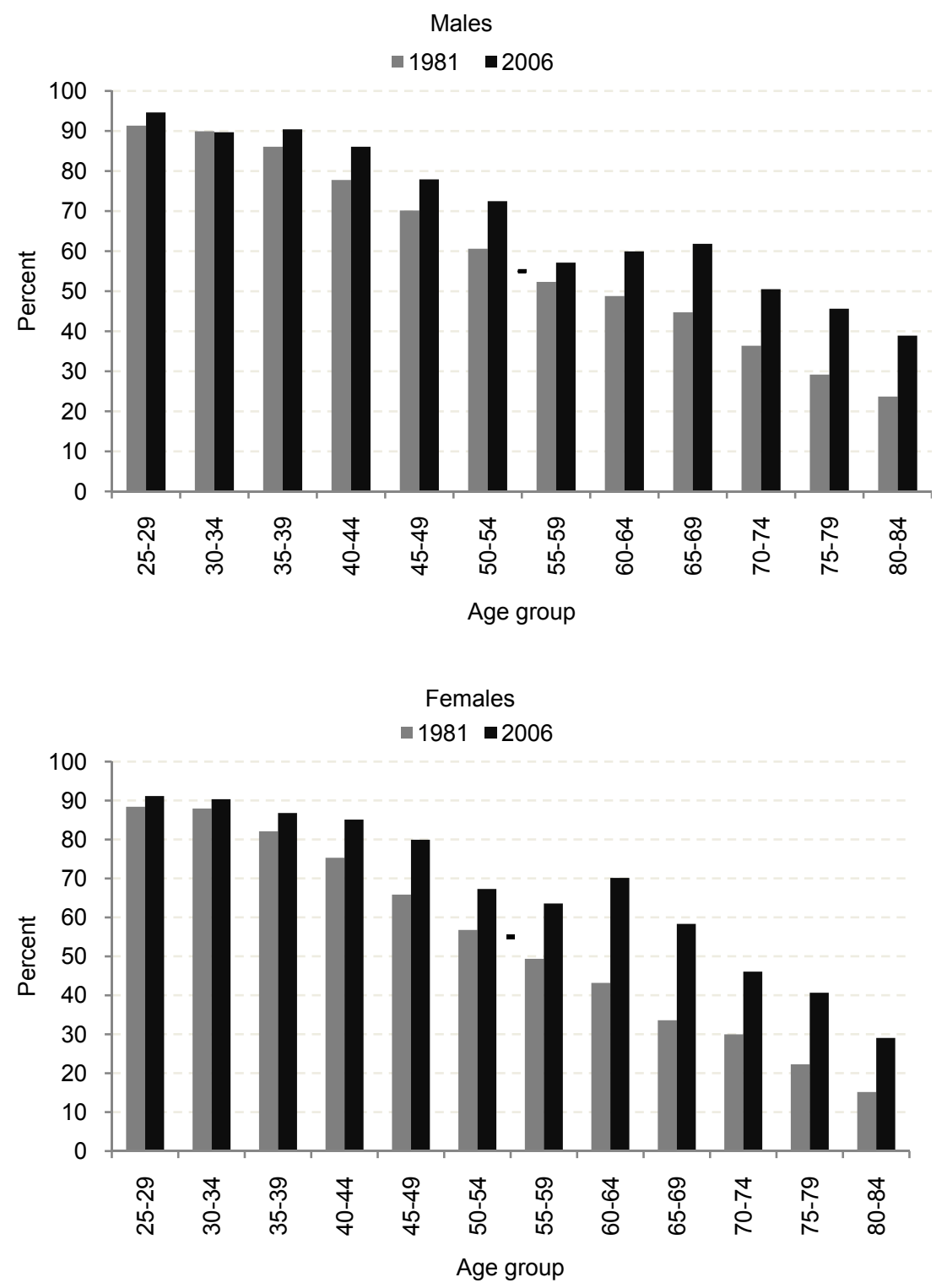

Source: Statistics Austria 
A very useful measure for an integrated description of life expectancy and self-rated health is health expectancy. ${ }^{1}$ Absolute health expectancy denotes the number of years an individual can expect ${ }^{2}$ to live in self-perceived good health; relative health expectancy denotes the ratio of absolute health expectancy to life expectancy. Health expectancy was calculated for Austria in 1991-2006 by Klimont (2008), who clearly confirmed an increase in population health. Doblhammer and Kytir (2001) calculated health expectancy for the elderly Austrian population for the years 1978-1998 and could provide similar results.

We may thus conclude that the increase in life expectancy in Austria during the last decades went along with a considerable improvement of the population's self-rated health status. The question is now whether this finding holds not only for the 'average' Austrian male or female, but also if broken down by education. Can we assume that all educational groups have equally gained length and quality of life during the last decades, or is there evidence that some educational groups have gained less than others or even lost? In the following sub-section we discuss the importance of that question.

\subsection{The educational dimension of health}

There is clear evidence that in developed countries today considerable variation in health outcomes exists between educational groups. Mortality data for Austria show that at the turn of the 21st century the life expectancy gap between people with a university degree and people with compulsory schooling only was about 6 years for males and 3 years for females (Klotz 2007). Comparable figures have been reported e.g. for German-speaking part of Switzerland (Spoerri et al. 2006) or Belgium (Deboosere et al. 2009), and a much larger gap has been found for Lithuania (Jasilionis et al. 2007). International comparisons suggest that in developed countries the mortality gap between the high and the low educated has typically not narrowed during the last decades of the 20th century (Valkonen 2001). Concerning morbidity, an interesting finding - for those countries where data is available - can be reported: the educational gradient in absolute health expectancy is usually larger than the gradient in life expectancy, i.e. despite their shorter lives the low educated spend on average more years in bad health than the high educated. Such a finding is documented e.g. for Austria, Norway, Finland, Belgium and the Netherlands (Crimmins and Cambois 2003) as well as for the United States (Molla et al. 2004).

The educational gradient of health outcomes is important for several reasons: First, education is one dimension of a person's socio-economic status, so the

The wording "health expectancy" is not universal; some authors use "healthy life expectancy" or "life expectancy in good health". Note that for other health measures than self-perceived health usually other terms are used, e.g. "disability-free life expectancy".

2 "Expectation" here refers to the period average, similar to period life expectancy. It should not be interpreted as a forecast for cohorts. 
educational gradient of health outcomes can be interpreted as a measure of social inequality in a society. Correspondingly, a change in the educational gradient indicates rising or falling inequality. High social inequality does not only disadvantage the lower social classes, but is costly for the entire population: Mackenbach et al. (2007) estimate that inequality-related losses of health amount to $1.4 \%-9.5 \%$ of GDP of EU countries. The European Commission has recognised that "policies that aim at promoting employment [at older ages] must take the differences between socioeconomic groups in terms of health conditions and health inequalities into account" (European Commission 2010).

Second, the high educated can be seen as a 'vanguard' group of the population (Shkolnikov et al. 2009), so the evolution of their health outcomes in the past is an important reference for the evolution of overall health outcomes in the future. Education-specific evolutions of life expectancy (and possibly health expectancy) may thus serve as important input in population projections. A further step is to explicitly account for education in a multi-state projection, as done by $\mathrm{KC}$ et al. (2010).

Moreover, given education is seen not only as a stratification variable of the population but itself as a 'driver of progress' of population health (as participation in higher education typically increases cognitive abilities, informational resources and self-control, as quoted by Deboosere et al. 2009), one may interpret the outcome gap between the high educated and the total population as a benchmark for the potential gain in overall population health by increasing the population's educational level. This is particularly important from a policy perspective since education can typically easier be influenced by policymakers than other socioeconomic variables such as occupation or income.

And last but not least, the education-specific evolution of life expectancy and health expectancy can considerably improve our understanding of the simultaneous evolution of length and quality of life. At present, relatively little is known-besides the sex dimension-about intra-country variation in the evolution of healthy years. There is reason to believe that the epidemiologic implications of declining death rates at older adult ages vary within a society, and that socio-economic variables like education are sources of variation. The education-specific evolution of life expectancy and health expectancy may thus provide useful input for further development of theories on the interdependencies between mortality and morbidity.

\subsection{Previous research for Austria}

The evolution of mortality risks by education has been studied for Austria in the 1980s by Doblhammer et al. (2005). Similar to other countries, they found an increase in relative inequality, particularly for middle-aged males. The analysis was extended to the 1990s by Klotz and Doblhammer (2008) who discovered that then the increase in relative inequality did not continue, and an absolute 
contraction occurred among females at retirement ages. No paper on the education-specific evolution of health expectancy has yet been published for Austria.

The value added of our paper is therefore as follows. First, we add latest figures on education-specific life expectancy in 2006, allowing us to investigate the evolution of educational mortality differences in the early 21 st century. Second, we combine mortality and morbidity information into education-specific health expectancies at ages 25-84 in 1981-2006. Such a long time series on education-specific health expectancies is exceptional for western Europe and provides answers to fundamental questions on intra-country variation in the evolution of quality of life during the last decades: Has the educational gradient of health expectancy changed since 1981? If yes, how is the change in the morbidity gradient related to a change in the mortality gradient? And to what extent did the change in the educational composition of the population contribute to overall health outcomes?

\section{Materials and methods}

\subsection{Educational levels}

In this paper we consider the highest education completed, summarised into three categories:

- high education, which means higher secondary or tertiary education (Matura, Hochschule),

- medium education, which means vocational schooling (Lehre, Fachschule),

- and low education, which means compulsory schooling only (Pflichtschule).

A summarisation into these three categories makes sense for clarity reasons, but also for the purpose of statistical reliability, particularly with respect to morbidity data. Our analysis does not include the part of the population that is under 25 years of age, so educational mobility between the three groups is small enough to be neglected.

In Table 1 the distribution of the Austrian population aged 25-84 with regard to the three educational groups is given for the censuses in 1981, 1991 and 2001 as well as for the 2006 register based census test. We clearly see an increase in the proportions high/medium educated and a concurrent decrease in the proportion low educated. This phenomenon is referred to as the educational expansion of the population, which has been more pronounced among females than males. 
Table 1:

Distribution (\%) of the Austrian population aged 25-84 years by educational level in 1981-2006

\begin{tabular}{l|r|r|r|r|r|r|r|r|r|c}
\hline \multirow{2}{*}{$\begin{array}{l}\text { Educational } \\
\text { level }\end{array}$} & \multicolumn{9}{|c|}{ Males } & \multicolumn{5}{c}{ Females } \\
\cline { 2 - 11 } & 1981 & 1991 & 2001 & 2006 & $\begin{array}{c}\text { Change } \\
2006-1981\end{array}$ & 1981 & 1991 & 2001 & 2006 & $\begin{array}{c}\text { Change } \\
2006-1981\end{array}$ \\
\hline High & 14 & 18 & 21 & 24 & 10 & 8 & 12 & 18 & 22 & 14 \\
Medium & 49 & 55 & 59 & 59 & 10 & 30 & 38 & 43 & 44 & 14 \\
Low & 37 & 28 & 20 & 17 & -20 & 62 & 50 & 40 & 35 & -28 \\
Total & 100 & 100 & 100 & 100 & 0 & 100 & 100 & 100 & 100 & 0 \\
\hline
\end{tabular}

Source: Statistics Austria

\subsection{Mortality and life expectancy}

Complete (single-year) life tables by educational level are based on linkage of census information with death certificates in 12-month follow-up periods. For the official 1981, 1991 and 2001 censuses this was done by statistical matching. Technical details and results were extensively described elsewhere (Doblhammer et al. 2005; Klotz 2007).

The latest life tables are based on linkage of the 2006 register based census test (no official Austrian census) with death records of the Austrian social security administration. A unique personal identifier available in both datasets (bereichsspezifisches Personenkennzeichen "Amtliche Statistik", bPK-AS) was used, making the linkage virtually complete: Compared with the previous follow-up data, a few deaths of people with no Austrian social security record may be missing, but this is numerically over-compensated by additional coverage of deaths abroad as well as more accurate linkage (since a unique identifier was used instead of statistical matching).

We present results on life expectancy at age 25 as well as on partial life expectancy at ages 25-84 (to provide a direct link to partial health expectancy).

\subsection{Self-perceived health status and health expectancy}

Cross-sectional data on health status of the Austrian population is available from the Austrian micro censuses (MCs) September 1978, December 1983, December 1991, September 1999 and from the Austrian health interview survey (HIS) that was conducted in March 2006-February 2007. The MCs were household surveys (proxy interviews were allowed), whereas the HIS was a personal survey. Detailed information on survey characteristics such as sample size, nonresponse or estimated design effects are given in Appendix Table 1. The estimated 
effective net sample size ${ }^{3}$ for our purposes (population aged 25-84, education known or imputed) ranged between 18,300 and 23,300 in the MCs and was 8,600 in the HIS.

Each survey contained a question (in German) on self-perceived health status. The question wording was identical in the MCs and very similar in the HIS. Possible answers were: very good, good, medium, bad and very bad. In this paper we combine very good and good respectively very bad and bad into one single category each. Self-perceived medium health is kept as an intermediate category.

All survey participants - without an upper age limit-were asked for selfperceived health status. It turns out, however, that figures for the oldest-old might be biased due to selective nonresponse of elderly people in bad health. For instance the HIS provides at ages $85+$ a proportion of the population in self-rated (very) good health that is $8-10$ percentage points higher than at ages $80-84$, what is very hard to believe given the pattern in Figure 3. To guarantee statistical validity, we thus decided to restrict the analysis to ages 25-84.

Missing values of education were imputed in the original data files of the 1991 and 1999 MCs as well as in the HIS, but not in the 1978 and 1983 MCs. Missing values of self-perceived health status were imputed in the HIS only. Detailed information is given in Appendix Table 1, however, item nonresponse was rather low in all surveys. The MCs were also subject to unit nonresponse on personal level, as the primary sampling units were households. We did not additionally impute any missing values for the purpose of our study. Of course we did use sample weights to adjust for sampling design and primary sampling unit nonresponse. For the MCs we did not use the original weights in the data files but new MC weights that were calibrated in a consistent manner for the entire period 1974-2003, as documented by Mitterndorfer (2008).

The MCs did not cover the institutionalised population but only people in private households. In the HIS the institutionalised population was in principle covered, but in practice under-represented. ${ }^{4}$ This means that health status estimates might in general be positively biased, but less so in the HIS than in the MCs.

The distribution of self-perceived health (good, medium, bad) was calculated for 5-year age groups $(25-29, \ldots, 80-84)$. Health expectancies at ages 25-84 were estimated by the Sullivan method (Jagger et al. 2001, see also Appendix). Health estimates from the 1978 and 1983 MCs were combined by simple averaging ${ }^{5}$ and

3 The effective net sample size is obtained by dividing the actual sample size by the design effect of the survey. The design effect is defined as the ratio of the actual variance of a linear statistic in the realised sample to its theoretical variance in a model simple random sample.

4 The actual proportion of the institutionalised population is about 1.0 per cent in Austria at ages 25-84, but in the HIS the institutionalised population accounts for only 0.4 per cent (both unweighted and weighted).

5 This averaging makes sense because the proportion of high educated females was still very low in advanced age groups around 1980, so by combining two surveys we can substantially improve the statistical reliability of our figures. 
then applied to the 1981/82 education-specific period life tables. The other surveys were each applied to one set of education-specific period life tables: the 1991 MC to the 1991/92 life tables, the 1999 MC to the 2001/2002 life tables and the $2006 / 2007$ HIS to the $2006 / 2007$ life tables. For simplicity reasons we refer to the periods of interest as 1981, 1991, 2001 and 2006.

Partial life expectancy at ages 25-84 can be decomposed into the following averages: years in self-perceived (very) good health, years in self-perceived medium health and years in self-perceived (very) bad health. Our primary interest concerns the evolution of years in self-perceived good health, both absolute and relative (i.e. as a percentage of partial life expectancy).

\subsection{Tests of significance of changes in educational differences}

Measured changes in educational differences can be caused either by true changes or by random variation. To assess the statistical reliability of measured changes, variances were calculated for (partial) life expectancies and absolute partial health expectancies. For life expectancy we used the formula of Chiang (1984: ch. 8), for health expectancy the formula of Mathers (as quoted by Davis et al. 1999). A detailed description is given in the Appendix.

Since we provide figures for three educational groups, three differences can be calculated: High vs. Medium, Medium vs. Low and High vs. Low. It follows that tests of significance are influenced by Type I error inflation. To keep the family-wise error rate at 0.05, we applied Holm's (1979) procedure, explained in the Appendix.

\subsection{Accounting for the educational expansion: the population attributable risk}

As pointed out before, the distribution of the Austrian population by educational level has essentially changed in the years 1981-2006. In a long-run time series it is therefore neccesary to account not only for the evolution of educational disparities in health outcomes, but also for the change in the educational composition of the population. This can be done by calculating population attributable risks (PARs). The PAR is defined as the difference of a health outcome (e.g. life expectancy) between the high educated and the total population (Mackenbach and Kunst 1997). It is therefore very easy to calculate and has an important meaning, namely the improvement that would be achieved in overall population health if it were possible to improve the outcomes of the medium/low educated to the level observed for the high educated. The PAR is influenced by the educational distribution of the population and consequently in a time series accounts for the change in that distribution over time. 


\section{Results}

\subsection{Overall and education-specific evolution of length and quality of life}

Life expectancy at age 25 has increased in Austria in 1981-2006 from 46.6 to 53.2 years for males und from 52.8 to 58.4 years for females (Table 2). The increase was thus 1 year larger for males than for females (6.6 respectively 5.5 years). Essentially the same increases - between 5.7 and 6.2 years for males, between 4.6 and 5.4 years for females - can be observed when broken down by educational level. It is important to note that any change in the educational gradient of life expectancy has therefore to be attributed to a smaller increase in one group, not to any decrease. ${ }^{6}$ Furthermore we see that the education-specific gains were smaller than the overall gains, a (statistical) consequence of the educational expansion of the population between 1981 and 2006.

Partial life expectancy at ages 25-84 has increased overall by 5.3 years for males and by 3.5 years for females. It turns out that the increases in partial health expectancy were even larger, namely 6.5 years for males and 8.1 years for females. That the partial health expectancy increase was larger than the partial life expectancy increase holds also when broken down by educational level, with the exception of low educated males (4.9 years increase in partial life expectancy, 4.1 years in partial health expectancy). Correspondingly, the expected number of years in self-rated medium health at ages 25-84 has stagnated or declined and the number of years in self-perceived bad health at ages 25-84 has not changed significantly in 1981-2006. ${ }^{7}$ Comparing males and females, it turns out that females gained more healthy years during the last decades, whereas males gained more total years.

6 In some eastern European countries the widening of the educational life expectancy gap in the 1990s was caused by a decrease in life expectancy of the low educated (Shkolnikov et al. 2006).

7 Note that the age group $85+$ is excluded from the analysis and that the expected lifetime at ages $85+$ has increased since 1981 , so the number of years in self-perceived bad health at all ages $25+$ might have evolved worse than at ages 25-84. 
Table 2:

Total and education-specific evolution of length and quality of life, Austria in 1981-2006

\begin{tabular}{|c|c|c|c|c|c|c|c|c|c|c|}
\hline \multirow{2}{*}{$\begin{array}{l}\text { Educational } \\
\text { level }\end{array}$} & \multicolumn{5}{|c|}{ Males } & \multicolumn{5}{|c|}{ Females } \\
\hline & 1981 & 1991 & 2001 & 2006 & $\begin{array}{c}\text { Change } \\
2006-1981\end{array}$ & 1981 & 1991 & 2001 & 2006 & $\begin{array}{c}\text { Change } \\
2006-1981\end{array}$ \\
\hline \multicolumn{11}{|c|}{ Life expectancy at age 25 (in years) } \\
\hline High & 50.6 & 53.0 & 55.2 & 56.3 & 5.7 & 55.1 & 57.6 & 58.9 & 59.8 & 4.6 \\
\hline Medium & 46.9 & 49.1 & 51.8 & 53.1 & 6.2 & 54.0 & 56.0 & 58.0 & 58.7 & 4.7 \\
\hline Low & 45.2 & 46.9 & 49.6 & 51.1 & 5.9 & 52.3 & 54.2 & 56.3 & 57.7 & 5.4 \\
\hline Total & 46.6 & 48.8 & 51.8 & 53.2 & 6.6 & 52.8 & 54.9 & 57.2 & 58.4 & 5.5 \\
\hline \multicolumn{11}{|c|}{ Partial life expectancy at ages $25-84$ (max. 60.0 years) } \\
\hline High & 49.5 & 51.4 & 53.1 & 53.6 & 4.1 & 53.1 & 54.5 & 55.4 & 55.7 & 2.6 \\
\hline Medium & 46.3 & 48.1 & 50.3 & 51.3 & 4.9 & 52.2 & 53.5 & 54.8 & 55.2 & 3.0 \\
\hline Low & 44.7 & 46.3 & 48.4 & 49.6 & 4.9 & 51.1 & 52.4 & 53.7 & 54.5 & 3.5 \\
\hline Total & 46.1 & 48.0 & 50.3 & 51.4 & 5.3 & 51.5 & 52.9 & 54.4 & 55.0 & 3.5 \\
\hline \multicolumn{11}{|c|}{ Absolute health expectancy at ages 25-84 (=years in self-perceived (very) good health) } \\
\hline High & 38.8 & 40.1 & 42.3 & 44.0 & 5.2 & 37.5 & 40.3 & 42.4 & 43.5 & 6.0 \\
\hline Medium & 30.8 & 32.7 & 35.5 & 36.4 & 5.5 & 33.2 & 36.1 & 39.0 & 40.2 & 7.0 \\
\hline Low & 27.0 & 27.3 & 29.9 & 31.1 & 4.1 & 27.8 & 29.5 & 32.1 & 32.3 & 4.6 \\
\hline Total & 30.4 & 32.2 & 35.4 & 37.0 & 6.5 & 30.2 & 32.8 & 36.2 & 38.3 & 8.1 \\
\hline \multicolumn{11}{|c|}{ Years at ages $25-84$ in self-perceived medium health } \\
\hline High & 8.7 & 8.5 & 8.0 & 7.3 & -1.3 & 11.5 & 11 & 10.3 & 9.2 & -2.3 \\
\hline Medium & 12.1 & 11.8 & 11.6 & 11.3 & -0.8 & 14.9 & 13.5 & 12.2 & 11.3 & -3.5 \\
\hline Low & 13.5 & 14.4 & 13.6 & 13.0 & -0.4 & 18.1 & 18.1 & 16.5 & 16.7 & -1.4 \\
\hline Total & 12.1 & 11.9 & 11.3 & 10.8 & -1.4 & 16.4 & 15.8 & 14.0 & 12.7 & -3.7 \\
\hline \multicolumn{11}{|c|}{ Years at ages 25-84 in self-perceived (very) bad health } \\
\hline High & 2.1 & 2.8 & 2.8 & 2.3 & 0.2 & 4.2 & 3.2 & 2.7 & 3.1 & -1.1 \\
\hline Medium & 3.4 & 3.6 & 3.2 & 3.6 & 0.2 & 4.2 & 3.9 & 3.6 & 3.7 & -0.5 \\
\hline Low & 4.3 & 4.6 & 4.8 & 5.4 & 1.2 & 5.2 & 4.8 & 5.0 & 5.5 & 0.3 \\
\hline Total & 3.5 & 3.8 & 3.6 & 3.6 & 0.1 & 4.9 & 4.3 & 4.2 & 4.0 & -0.8 \\
\hline
\end{tabular}

Notes: The years at ages 25-84 in self-perceived (very) good, medium and (very) bad health sum up to partial life expectancy at ages 25-84. Life expectancy at age 25 was calculated by census follow-up, so the totals slightly differ from the official (cross-sectional) Austrian life expectancy values for the respective calendar years.

Source: Statistics Austria 


\subsection{The educational gradient}

Table 3 presents the evolution of differences in years of life expectancy, partial life expectancy and partial health expectancy for pair-wise comparisons of educational groups (High vs. Medium, Medium vs. Low, High vs. Low). Statistically significant changes in mentioned differences between 1981 and 2006 are marked.

Table 3:

Evolution of educational differences (years) in length and quality of life, Austria in 1981-2006

\begin{tabular}{|c|c|c|c|c|c|c|c|c|c|c|c|}
\hline \multirow[b]{2}{*}{$\begin{array}{l}\text { Difference between } \\
\text { educational levels }\end{array}$} & \multicolumn{5}{|c|}{ Males } & & \multicolumn{5}{|c|}{ Females } \\
\hline & 1981 & 1991 & 2001 & 2006 & $\begin{array}{c}\text { Change } \\
2006- \\
1981\end{array}$ & & 1981 & 1991 & 2001 & 2006 & $\begin{array}{c}\text { Change } \\
2006- \\
1981\end{array}$ \\
\hline \multicolumn{12}{|c|}{ Life expectancy at age 25} \\
\hline High vs. Medium & 3.7 & 3.9 & 3.4 & 3.2 & -0.5 & & 1.1 & 1.6 & 0.9 & 1.0 & -0.1 \\
\hline Medium vs. Low & 1.7 & 2.1 & 2.3 & 2.0 & 0.3 & & 1.7 & 1.8 & 1.7 & 1.0 & $-0.7 *$ \\
\hline High vs. Low & 5.4 & 6.0 & 5.7 & 5.2 & -0.2 & & 2.8 & 3.4 & 2.6 & 2.0 & $-0.8 *$ \\
\hline \multicolumn{12}{|c|}{ Partial life expectancy at ages $25-84$} \\
\hline High vs. Medium & 3.1 & 3.2 & 2.8 & 2.3 & -0.8 & $*$ & 0.9 & 1.0 & 0.5 & 0.5 & -0.3 \\
\hline Medium vs. Low & 1.6 & 1.9 & 1.9 & 1.7 & 0.1 & & 1.2 & 1.0 & 1.1 & 0.7 & $-0.5 *$ \\
\hline High vs. Low & 4.7 & 5.1 & 4.6 & 4.0 & -0.8 & * & 2.1 & 2.1 & 1.7 & 1.2 & $-0.9 *$ \\
\hline \multicolumn{12}{|c|}{ Absolute health expectancy at ages $25-84$} \\
\hline High vs. Medium & 7.9 & 7.4 & 6.8 & 7.6 & -0.3 & & 4.3 & 4.1 & 3.4 & 3.3 & -1.0 \\
\hline Medium vs. Low & 3.8 & 5.3 & 5.6 & 5.2 & 1.4 & & 5.4 & 6.7 & 6.9 & 7.9 & $2.5 *$ \\
\hline High vs. Low & 11.7 & 12.8 & 12.4 & 12.9 & 1.1 & & 9.7 & 10.8 & 10.2 & 11.1 & 1.4 \\
\hline
\end{tabular}

Notes: The sum of the differences High vs. Medium and Medium vs. Low equals the difference High vs. Low.

* p-values change statistically significant at the multiplicity-adjusted .05 level (for details see Appendix).

Source: Statistics Austria

For males we observe no significant change in life expectancy differences between educational groups during the last decades. The difference between the high and the low educated was 5.2 years in 2006, almost the same as in 1981 (5.4 years). A significant decline in the gap between high and medium/low educated males can be observed for partial life expectancy, but this has to be qualified as the high educated had less potential to gain lifetime in that age group. No significant change in differences also occurred for partial health expectancy. In 2006 the measured difference between the high and the low educated was 12.9 years, in 1981 it was 11.7 years. 
For females, however, we observe a different pattern: the difference in life expectancy between the high/medium and the low educated has significantly declined between 1981 and 2006 (from 1.7 to 1.0 years between the medium and the low educated, from 2.8 to 2.0 years between the high and the low educated). Also the partial life expectancy gap has decreased between high/medium and low educated females, though again this has to be qualified given the different potentials for improvement. On the contrary, the partial health expectancy gap between the medium and the low educated has significantly increased from 5.4 to 7.9 years (between the high and the low educated the measured difference increased from 9.7 to 11.1 years, which was no statistically significant change). Apparently the reduction of mortality risks at older adult ages had different epidemiologic implications between medium and low educated females.

A closer look at the numbers in Table 3 reveals that for both sexes each measured difference between the high and the medium educated was lower in 2006 than it was in 1981, whereas this does not hold for differences between the medium and the low educated in general. This highlights the fact that the educational gradient of health outcomes can evolve more complexly than simply 'increase or decrease'. It is also interesting to look at the evolution of the educational differences in the intermediate periods: whereas for life expectancy the measured gaps were typically largest in 1991, for partial health expectancy no such concentration can be observed; indeed, with respect to female partial health expectancy, the maximum measured gap between the high and the medium educated occurred in 1981, whereas the maximum measured gap between the medium and the low educated occurred in 2006.

\subsection{Relative health expectancy}

Figure 4 shows the evolution of partial relative health expectancy in 1981-2006, i.e. the proportion of years lived in self-perceived good health out of all years lived at ages 25-84. We observe a long-term increase for all educational groups; precisely, the education-specific proportion of healthy years has increased by 2-4 percentage points for males (overall increase 6 percentage points) and by 5-9 percentage points for females (overall increase 11 percentage points). Moreover, we observe a rather decreasing gap between the high and the medium educated compared with a rather increasing gap between the medium and the low educated. 
Figure 4:

Total and education-specific relative health expectancy at ages 25-84. Austria in 1981-2006
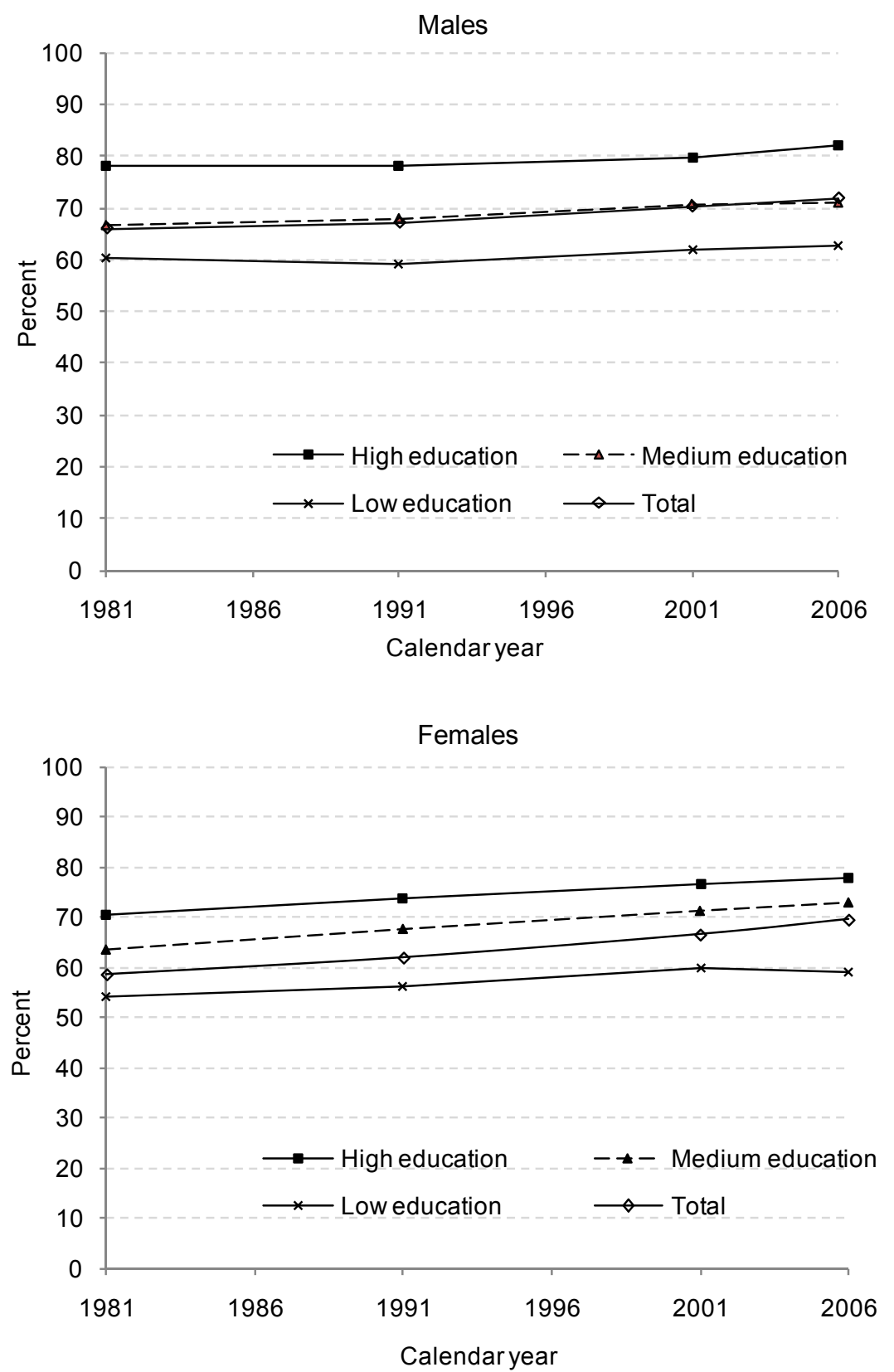

Note: Relative health expectancy denotes the proportion of years in self-perceived (very) good health to all years lived at ages 25-84.

Source: Statistics Austria 


\subsection{The population attributable risk}

To analyse the simultaneous influence of educational expansion and the educational gradient on population health in an integrated way, we calculated population attributable risk (PAR) figures for life expectancy, partial life expectancy and absolute partial health expectancy (Table 4). It turns out that for length as well as quality of life the difference between the high educated and the total population has decreased for both sexes in the period 1981-2006. For males the decline in the PAR of life expectancy and partial health expectancy was in both cases about 1 year. For females the PAR of life expectancy has declined also by about 1 year, whereas the PAR of partial health expectancy has declined even by about 2 years. A closer look at the intermediate periods reveals that the PARs stagnated in the 1980s, whereas they decreased in the 1990s and-with the exception of male health expectancy - also thereafter.

Table 4:

Evolution of the population attributable risk (years) of length and quality of life, Austria in 1981-2006

\begin{tabular}{l}
\hline \\
\cline { 2 - 3 }
\end{tabular}

Note: The population attributable risk (PAR) denotes the difference between the high educated and the total population.

Source: Statistics Austria

The evolution of the PARs emphasises the independent explanatory effect of the educational expansion on population health: though the educational gradient of female partial health expectancy has not declined in 1981-2006, the disparity between the high educated and the total population was about 2 years lower in 2006 than it was in 1981. In short, the educational expansion has shifted a large proportion of the population to lower-risk groups. 


\section{Discussion}

\subsection{Possible weaknesses of the data}

In the (paper and pencil) censuses conducted in the time span 1981-2001 the question on educational attainment was compulsory for the entire population from age 15 onwards. Nonresponse was caused either by refusal to answer or by proxy fill-ins of census forms and was corrected by imputation. In the 2001 census the nonresponse rate was overall 4.0 per cent (thereof 2.8 per cent refusals and 1.2 per cent proxy fill-ins). A disproportionately high nonresponse rate was observed for foreigners, the non-employed and the oldest-old. The higher nonresponse rate for the population aged $80+$ was primarily caused by proxy fill-ins by institutional staff or municipal authorities who answered for people who were not able to speak for themselves. It is clear that such proxy fill-ins for the elderly often regarded people in bad health (e.g. in institutions or hospitals), and indeed in the follow-up period we observed a disproportionately high mortality risk for nonrespondents. This means that imputation of missing education values in the censuses can influence our results on educational mortality differences. For the 2001 census, a sophisticated hot-deck imputation procedure was applied (Schwabe 2005) and those imputed values were also used at the 2006 register based census test. For the 1981 and 1991 censuses, however, missing education values were simply imputed as low education, implying that life expectancy of the low educated might be under-estimated for 1981 and 1991. Unfortunately it was not possible to re-identify nonrespondents in the 1981 and 1991 census files. For the 2001 census a sensitivity analysis was carried out to test what effect it would have had on educational mortality differences if we had imputed all missing values simply as low education, as it was the case in 1981 and 1991: Life expectancy at age 25 would have been under-estimated for the low educated by 0.2-0.3 years, whereas for the medium/high educated it would have been overestimated by $0.2-0.4$ years. ${ }^{8}$ We conclude that the life expectancy gaps between the high/medium and the low educated might be biased upwards for the 1981 and 1991 results (the influence on the difference High vs. Medium is negligible).

In the follow-up studies for the 1981-2001 censuses, about $10 \%$ of all death certificates could not be linked to any census record. An important reason for non-linkage is residential mobility, as last residential address of the deceased was one of the matching variables, so people that had moved between census and death - e.g. into a nursery home - could not be linked. Also the death records for the 1981-2001 results did not contain deaths abroad, i.e. of people residing in Austria but dying abroad. It is possible that the probability of residential mobility or of dying abroad differs by educational level. Our results for the 2006

\footnotetext{
When restricted to partial life expectancy at ages 25-84, for 2001 the simple imputation would have resulted in under-estimation for the low educated by $0.1-0.2$ years and over-estimation for the high/medium educated by 0.2 years.
} 
follow-up, where almost all deaths could be linked and deaths abroad were included, might therefore be more accurate than the figures for the previous periods.

Different handling of missing values - of both education and self-rated health - also refers to survey data. No imputation (available-case method) was made in the 1978 and 1983 MCs, whereas hot-decking was applied in the 1991 and 1999 MCs as well as in the HIS. Moreover, the MCs were also subject to unit nonresponse on personal level, as the primary sampling units were households. The comparability of self-perceived health is also influenced by different proportions of proxy interviews. Proxy interviewing was generally allowed in the MCs and there accounted for about $30-35 \%$ of all interviews for males and $15 \%$ for females, whereas in the HIS, where proxy interviewing was allowed only if the respondent was for health reasons unable to answer, proxy interviews accounted for only about $2 \%$ of all interviews (see Appendix Table 1). We conclude that our figures on self-rated health might be more accurate for 2006 than for the earlier periods, particularly for males.

The MCs did not cover the institutionalised population but only people in private households. In the HIS the institutionalised population was in principle covered, but in practice under-represented. One can reasonably assume that the institutionalised population is in worse health than the non-institutionalised population, particularly among the elderly. Appendix Table 2 reports the proportion institutionalised among the population aged 65-84 in Austria, by sex and 5-year age groups, for all censuses conducted in the years 1981-2006 and for the 2001 census also by education. The proportions are clearly higher for females than males and have slightly decreased for both sexes in 1981-2006. In 2001 the proportion institutionalised was higher for the low educated than for the medium/high educated for males in general and for females particularly at ages 75-84. We conclude that exclusion respectively under-coverage of the institutionalised population in surveys might cause an over-estimation of healthy years at ages 25-84, particularly for females, the low educated, and the periods before 2006 .

\subsection{Possible weaknesses of the measures}

Health expectancies were calculated by the Sullivan method, using cross-sectional survey data on self-perceived health. Concerning the pros and cons of the Sullivan method, a lot has been discussed in the literature, here we simply refer to Laditka and Hayward (2003).

Self-perceived health was chosen as the health variable because it provides the longest possible consistent time series for Austria (since 1978, which we combined with 1983 to our 1981 figures). Various other health variables have been used in international studies, whereof the two most famous ones are prevalence of disability (or chronic illness) and functional limitations in daily 
activities. Self-perceived health has the advantage that it covers physical as well as mental and social dimensions of well-being, and is therefore close to the official WHO definition of health. ${ }^{9}$ Though a subjective measure, studies have shown a strong correlation with objective health variables both cross-sectional (Urban and Klimont 2002) and longitudinal (Idler and Benyamini 1997, as quoted by Urban and Klimont 2002). Compared with objective health variables, selfperceived health is usually easier to obtain in surveys, particularly in large surveys of public agencies. However, it can be affected by variation in symptom attention across different parts of the population. Furthermore, as it is a subjective measure, interview effects might have an increased impact.

We generally computed summary measures of mortality and morbidity. The evolution of such summary measures can hide age-specific trends. Figure 3 indicates $^{10}$ that the improvement in self-perceived health in 1981-2006 was comparably small at advanced working ages (say, 55-64 years for males and 50-59 years for females). Furthermore, our analysis does not include selfperceived health at ages $85+$. The evolution of relative health expectancy at ages 25-84 thus probably over-estimates the evolution of relative health expectancy at all ages $25+$, as the expected lifetime at ages $85+$ has increased.

\subsection{Consistency with previous findings for Austria}

Our data on mortality in the years 1981-2001 is essentially the same as used by Klotz and Doblhammer (2008), ${ }^{11}$ so our results naturally reproduce their findings for 1981-2001: a rather increasing life expectancy gap in the 1980s and a reversal thereafter. Concerning the evolution of education-specific life expectancy in 2001-2006, it seems that the trend observed for the 1990s has essentially persisted in the early 21 st century. Obviously the measured life expectancy difference between the high and the low educated reached a maximum in 1991 and has decreased since then.

"Health is a state of complete physical, mental and social well-being and not merely the absence of disease or infirmity." Preamble to the Constitution of the World Health Organization as adopted by the International Health Conference, New York, 19-22 June, 1946; signed on 22 July 1946 by the representatives of 61 States (Official Records of the World Health Organization, no. 2, p. 100) and entered into force on 7 April 1948.

10 The underlying data can be found in Appendix Table 3, where also the education-specific values are reported.

11 Klotz and Doblhammer (2008) report life expectancies at age 35, our paper at age 25. Furthermore, they distinguished five educational levels, whereas our analysis summarises those five levels into three levels. 


\subsection{Comparison with results from other countries}

Only some countries provide regular information on mortality disparities by educational attainment or other socio-economic criteria. For those western European populations where data on the evolution of educational mortality disparities is available either an increase or stagnation of life expectancy disparities during the last decades was reported. For instance the life expectancy gap between the highest and the lowest educational group increased in Belgium 1991-2004 (Deboosere et al. 2009), Denmark 1994-2005 (Brønnum-Hansen and Baadsgaard 2008), or the city of Turin 1971-1995 (Valkonen 2001: ch. 3.6, restricted to partial life expectancy). An increase in life expectancy disparities was typically caused by a comparably small increase or even decrease in life expectancy of the lowest educational group, whereas the gap between the highest educational group and the medium educational groups not generally widened. For the city of Barcelona stagnation in educational disparities in adult mortality was observed in 1992-2003, measured by age-standardised mortality rates (Borrell et al. 2008). Also measured by other socio-economic variables than education mortality disparities in western Europe either increased or stagnated after 1970, e.g. in Finland 1971-1995 (Valkonen 2001: ch. 3.4, social class), England and Wales 1972-2005 (Johnson 2007, occupation-based social class), France (Cambois et al. 2001, 3 occupational classes, 1980-1991, males only; Leclerc et al. 2006, 7 occupational classes, 1968-1996), or the city of Rome 1990-2001 (Cesaroni et al. 2006, ecological study, index of socio-economic position).

Our results for Austria do not show a disproportionately low life expectancy increase for the low educated but rather the contrary. At a first glance we could thus conclude that - at least in terms of trends - in Austria the situation was comparably favourable for the low educated during the last decades, but this has to be qualified for two reasons: first, international comparisons are influenced by different educational compositions of the populations, and in Austria the low educated account for a relatively high proportion of the population, implying that this population is probably more heterogeneous than in other countries. In particular, the Austrian data do not (and cannot) distinguish between people with no education completed and people who have completed compulsory school. Data from Belgium (Deboosere et al. 2009) indicate that those with no education completed might have been a particular risk group with respect to the evolution of life expectancy, whereas those who have completed compulsory school not necessarily have been. Second, international comparisons are sensitive with respect to the periods analysed. Our data for Austria indicate a decreasing life expectancy gap in 1991-2006, but an increasing gap in 1981-1991. Also data for England and Wales (Johnson 2007) and for Finland (Valkonen 2001: ch. 3.4) show that the change in social class differences regarding life expectancy was not linear over time. 
Concerning trends in health expectancy disparities, even much less data is available from other countries. Trends by education were reported for the Netherlands 1989-2000 (Perenboom et al. 2005, chronic morbidity) and Denmark 1994-2005 (Brønnum-Hansen and Baadsgaard 2008, three health measures). By other socio-economic classification variables results are available for Sweden 1976-1990 (Pettersson 1995, as quoted by Crimmins and Cambois 2003, occupational class, composite health index), France 1980-1991 (Cambois et al. 2001, occupational class, disability, males only) and England 1994-1999 (Bajekal 2005, ecological study, deprivation deciles, two health measures). For the Netherlands, Sweden and Denmark an increasing health expectancy gap was reported between the highest and the lowest class, whereas differences between the highest class and the medium classes not generally increased. No significant changes were reported for France and England. Thus in Austria the evolution of the health expectancy gap seems to be at most on average from the viewpoint of the low educated - contrary to the evolution of the life expectancy gap, where the Austrian trend seems favourable for the low educated. Note again, however, that this comparison has to be qualified since educational classifications and compositions, periods of analysis, and-moreover-health measures differ between countries.

\subsection{Possible explanations for trends in educational disparities}

There has been a wide discussion in the literature - both theoretical and empirical-about possible explanations for socio-economic disparities in mortality and morbidity. Valkonen (2001: ch. 3.2) summarises various contributions into selection effects, structural/materialist explanations and behavioural/cultural explanations. Kunst (1997: ch. 11.5) uses the concept of 'equifinality' to generalise the association between socio-economic status and health, with special focus on the causal directions of relationships. In a very comprehensive German paper, Schneider (2008) formalises a multi-dimensional model for the social gradient of morbidity and mortality, identifying seven explanatory theses and discussing possible interaction effects. ${ }^{12}$

Regarding our paper, two restrictions have to be considered: first, most of those models refer to a merely abstract socio-economic status rather than explicitly to education. ${ }^{13}$ Second, such models are typically designed to explain an observed disparity, not its derivative with respect to time. The main focus of our paper however is trends in disparities.

12 An interesting example of the multi-dimensional approach is that Schneider (2008) links "access to health care" not only to structural factors like coverage of health insurance, but also to cultural factors like communication between doctor and patient.

13 Kunst (1997: ch. 11.5) is an exception, clearly distinguishing between resources (=education), rewards (=income) and their linkage (=occupation). 
The second restriction is not very limiting: by introducing a dynamic element into the various hypotheses, we obtain explanations for changes over time. For instance, if educational disparities in health outcomes are caused by disparities in average incomes (materialist/structural), then a change in the average income gap is likely to result in a changing health gap. Analogous, if different smoking habits contribute to educational disparities in health (cultural/behavioural), then an education-specific evolution of smoking habits might result in education-specific evolution of health outcomes. ${ }^{14}$ Similarly, changes in selection effects may contribute to trends in educational inequalities in morbidity and mortality. What should however be considered is that a change in explanatory factors does not necessarily result in changing health outcomes at once; in this case, a time-lag is more likely.

Our results indicate that most educational differences in length and quality of life were rather stable during the last decades. Between medium and low educated females, however, the life expectancy gap has significantly decreased but the health expectancy gap significantly increased. What can we say about possible explanations for that deviation? Clearly our data alone do not enable us to answer the question, but external information may give some hints which factors could have influenced relative morbidity risks of low educated females to a greater extent than their relative mortality risks. Unfortunately for Austria no educationspecific time series is available for behavioural risk factors such as smoking ${ }^{15}$ or obesity. What can be studied is the education-specific evolution of variables such as family status, labour force participation, or citizenship, which are available from census files and have been reported in international literature as explanatory factors for health inequalities (Shkolnikov et al. 2009; Leclerc et al. 2006; Kohls 2008a; b).

14 Kuntsche and Gmel (2005) discuss education-specific trends in smoking habits in Switzerland, with explicit reference to the "theory of diffusion of innovations".

15 Urbas and Klimont (2002: p. 93) published data on education-specific smoking rates in Austria in 1979-1997. Unfortunately their educational classification does not allow distinguishing between the medium and the low educated as classified in our paper. Nonetheless their figures seem to indicate that, among females aged 30-59, both the proportion of current smokers and the proportion of ever smokers have increased disproportionately for the low educated. 
Table 5:

Austrian females aged 30-59 years: Education-specific \% of total, 1981 vs. 2001

\begin{tabular}{|c|c|c|c|}
\hline Educational level & 1981 & 2001 & $\begin{array}{c}\text { Change } \\
2001-1981\end{array}$ \\
\hline \multicolumn{4}{|c|}{ Family status: Married or cohabiting } \\
\hline High & 67.4 & 64.2 & -3.1 \\
\hline Medium & 76.9 & 73.2 & -3.7 \\
\hline Low & 77.2 & 71.2 & -6.0 \\
\hline Total & 76.3 & 70.8 & -5.6 \\
\hline \multicolumn{4}{|c|}{ Family status: Single mother } \\
\hline High & 9.5 & 12.3 & 2.8 \\
\hline Medium & 8.8 & 11.4 & 2.7 \\
\hline Low & 8.8 & 10.7 & 1.9 \\
\hline Total & 8.8 & 11.3 & 2.5 \\
\hline \multicolumn{4}{|c|}{ Labour force participation: Employed } \\
\hline High & 67.1 & 78.4 & 11.3 \\
\hline Medium & 58.7 & 66.2 & 7.5 \\
\hline Low & 47.1 & 52.3 & 5.3 \\
\hline Total & 52.7 & 64.2 & 11.6 \\
\hline \multicolumn{4}{|c|}{ Labour force participation: Unemployed } \\
\hline High & 1.0 & 3.0 & 2.0 \\
\hline Medium & 1.4 & 4.1 & 2.7 \\
\hline Low & 1.4 & 5.9 & 4.4 \\
\hline Total & 1.4 & 4.4 & 3.0 \\
\hline \multicolumn{4}{|c|}{ Citizenship: Non-EU-15 citizen } \\
\hline High & 2.6 & 6.0 & 3.4 \\
\hline Medium & 0.6 & 2.7 & 2.1 \\
\hline Low & 3.8 & 14.6 & 10.8 \\
\hline Total & 2.6 & 7.2 & 4.6 \\
\hline
\end{tabular}

Note: EU-15 refers to EU member states in 2003.

Source: Statistics Austria

Table 5 reports some education-specific proportions for females aged 30-59 of Austria in 1981 vs. 2001. With regard to family status, we see that the proportion married or cohabiting as well as the proportion of single mothers has evolved relatively similar across educational groups in 1981-2001, so at a first glance family status is little likely to explain the different evolution of morbidity vs. mortality. Concerning labour market participation, the increase in employment rates is positively correlated with education, whereas for unemployment the opposite holds. As higher employment rates typically result in higher (household) incomes, whereas unemployment is typically associated with poverty and stress, changes in the labour market during the last decades are one possible explanation for the increasing health expectancy gap between medium and low educated females. A particular large educational disparity can be observed for the increase 
in the proportion of Non-EU-15 ${ }^{16}$ citizens, which was much larger for the low educated than for the medium/high educated. For migrants in Austria there was reported a worse self-rated health status (Klimont et al. 2008: ch. 7) but larger life expectancy than for native Austrians (Bauer and Kytir 2010). ${ }^{17}$ The rising importance of the migrant population among the low educated thus provides one reasonable explanation for the deviation in the evolution of life expectancy difference vs. health expectancy difference between medium and low educated females. However, the fact that no such deviation can be observed among males remains questionable.

\subsection{Education and socio-economic status}

That most explanatory theses for educational inequalities in health refer to socioeconomic status, not actually to education, needs some more discussion. Most researchers might agree that education contributes to a person's socio-economic status. Only a few, however, clearly distinguish in analyses between education and other socio-economic classification variables. The specific problem in a time series is that because of the educational expansion of the population during the last decades it is questionable if and to which extent educational categories are comparable over time. ${ }^{18}$

Crimmins and Cambois (2003) distinguish between an absolute and a relative approach. The absolute approach can be motivated from the theory of human capital (Becker 1993) and interprets educational attainment as a measure of cognitive and social abilities. Thus educational groups are seen as more or less homogeneous populations with respect to health risks, and any change in the educational distribution of the population is itself a contribution to rising or falling health inequality. The relative approach instead can be motivated from social stratification theory (e.g. Bergman and Joye 2001) and interprets educational attainment as a measure of relative position within a society. Health outcomes are assumed to depend on the relative socio-economic position in such a way that a change in the educational distribution of the population is merely a 'disturbance term' in time series, as members of one and the same educational category are not comparable over time with respect to their relative positions.

We do not strictly decide on one of those approaches here; from our point of view, both the absolute and the relative approach have their strengths and

16 "EU-15" refers to EU member states in 2003.

17 Figures in Table 5 and of Bauer and Kytir (2010) refer to foreign citizenship, whereas Klimont et al. (2008) refer to foreign citizenship or foreign country of birth. Country of birth was asked in the 2001 census, but not in the 1981 census.

18 Strictly speaking, this is not an exclusive problem of education but refers also to e.g. occupational class, as the proportion of non-manual employees has typically increased in developed countries during the last decades whereas the proportion of manual workers has decreased. However, changes in the educational distribution were exceptionally large (e.g. Martikainen et al. 2007). 
weaknesses. It is interesting to see that the fundamental change in the educational distribution of the population during the last decades has not resulted in a large change in differences between educational groups, but in a decline of population attributable risks. This finding is particularly impressive for female quality of life: on the one hand, the partial health expectancy gap between the high and the low/medium educated was statistically equal in 2006 and 1981. On the other hand, the difference between the high educated and the total population has declined by about 2 years, the largest decline of all population attributable risks observed. In other words, when interpreting the high educated as a 'vanguard group' of the population, the difference between the vanguard group and the total population has remarkably declined in the recent past, and this decline was caused by numerical expansion of the vanguard group, not by a reduction of differences between the vanguard group and the non-vanguard groups. This clearly illustrates that an analysis of health outcomes by education "concerns both inequality and progress", as Deboosere et al. (2009: p.177) have pointed out.

The comparability of a person's educational level as a measure for socioeconomic status is more questionable for females than males for two reasons: first, the educational expansion of the population was more pronounced among females. Second, changing gender roles (which are of course related to the educational expansion) have probably raised the importance of a woman's own educational level for her socio-economic status. In earlier times low education was not uncommon among females also in the middle classes, and for married women - frequently out of the labour market - social class affiliation was often measured by characteristics of the husband. ${ }^{19}$ Today, however, low education is also among females highly correlated with lower social class, with the exception of the oldest cohorts. This fact somehow reveals that some of the values in Table 5 could explain more than they seem at a first glance: For instance, we saw that the education-specific declines in the proportion married or cohabiting were not tremendously different, and firstly concluded that family status is little likely to explain the widening health expectancy gap between medium and low educated females. Nonetheless, even the fact that the proportion married or cohabiting has at all declined could be an explanatory factor, given that this has increased the importance of a woman's own educational attainment as a predictor for her socioeconomic status.

9 An example in research on differential mortality is Pamuk's (1985) famous paper on social class inequalities in mortality in England and Wales from 1921 to 1972, where the female population is included only insofar as married women are classified by the occupation of the husband. 


\section{Summary and conclusions}

All educational groups have seen a considerable increase in both length and quality of life in 1981-2006. When discussing the evolution of the educational gradient, it is therefore important to note that any change in a gap was the result of a slower progress in one group, not of a regress. Also relative health expectancy, i.e. the proportion of years in self-perceived good health out of all years lived at ages 25-84, has increased for both sexes and all educational groups.

The educational gradient of health can evolve more complexly than simply 'increase or decrease'. We found an at most constant, rather contracting health expectancy gap between high and medium educated females, but a widening health expectancy gap between medium and low educated females. This implies that simple comparisons of extreme categories may produce misleading conclusions on the evolution of the pattern of inequality. In particular, one should distinguish between cases where educational/socio-economic disparities in general increase and cases where only a particular class deviates from the average trend. This is also supported by the findings from other countries, where typically the lowest class saw an unfavourable evolution of health expectancy (in some countries also life expectancy), but the gap between the highest class and the medium classes not generally widened.

We recognise that a more or less homogeneous increase in length of life across different subpopulations within a country does not necessarily imply a homogeneous increase in quality of life. Trends in life expectancy disparities may differ from trends in health expectancy disparities. There is reason to believe that the epidemiologic implications of declining mortality risks at older adult ages vary within a society, and that education (and related to it, socio-economic status) is one source of that variation. Policy implications like "we should reduce the gap in life expectancy" are little useful if only length of life is considered but quality of life ignored. Also we found a larger increase in life expectancy for males, but a larger increase in health expectancy for females.

And finally, any long-run comparison of educational health inequalities should account for both the educational gradient and the educational expansion. On the one hand, most health differences between educational categories have remained rather constant in 1981-2006. On the other hand, the educational expansion of the population during the last decades has shifted a large proportion of the population to lower-risk groups, and this has improved overall population health outcomes. Quoting Deboosere et al. (2009: p.177), "Historically, the improvement in the educational level of a population reflects the progress to reduce risks with a negative impact on health." Our findings clearly indicate that this 'historical' reflection is not at all out-of-date. 


\section{Acknowledgements}

We would like to thank Adelheid Bauer, Petra Ihle, Jeannette Klimont and Josef Kytir from Statistics Austria for providing data and comments for this article. We extend our gratitude to two anonymous reviewers for very helpful comments and suggestions for improvement on an earlier draft of the paper.

\section{References}

Bajekal, M. 2005. "Healthy life expectancy by area deprivation: magnitude and trends in England, 1994-1999.” Health Statistics Quarterly 25: 18-27.

Bauer, A. and J. Kytir. 2010. "Sterbefälle auf ausländischem Staatsgebiet." Statistische Nachrichten 65(5): 376-382.

Becker, G. 1993. Human Capital. A theoretical and empirical analysis, with special reference to education. Third edition, Chicago, University of Chicago Press.

Bergman, M. and D. Joye. 2001. "Comparing social stratification schemas: CAMSIS, CSP-CH, Goldthorpe, ISCO-88, Treiman, and Wright." Cambridge Studies in Social Research 9: 1-31.

Borrell, C., E. Azlor, M. Rodríguez-Sanz, R. Puigpinós, G. Cano-Serral, M. Pasarín, J. Martínez, J. Benach, and C. Muntaner. 2008. "Trends in socioeconomic mortality inequalities in a southern European urban setting at the turn of the 21st century." Journal of Epidemiology and Community Health 62(3): 258-266.

Brønnum-Hansen, H. and M. Baadsgaard. 2008. "Increase in social inequality in health expectancy in Denmark." Scandinavian Journal of Public Health 36(1): 44-51.

Cambois, E., J. Robine, and M. Hayward. 2001. "Social inequalities in disability-free life expectancy in the French male population, 1980-1991." Demography 38(4): 513-524.

Cesaroni, G., N. Agabiti, F. Forastiere, C. Ancona, and C. Perucci. 2006. "Socioeconomic differentials in premature mortality in Rome: changes from 1990 to 2001." BMC Public Health 6: 270.

Chiang, C. 1984. The life table and its applications. Malabar: Krieger.

Crimmins, E. and E. Cambois. 2003. "Social inequalities in health expectancy." In: J. Robine et al. (eds.) Determining Health Expectancies. Chichester, Wiley, pp. 111-125.

Davis, P., P. Graham, and N. Pearce. 1999. "Health expectancy in New Zealand, 19811991: social variations and trends in a period of rapid social and economic change." Journal of Epidemiology and Community Health 53(9): 519-527.

Deboosere, P., S. Gadeyne, and H. Van Oyen. 2009. "The 1991-2004 evolution in life expectancy by educational level in Belgium based on linked census and population register data." European Journal of Population 25(2): 175-196.

Doblhammer, G. and J. Kytir. 2001. "Compression or expansion of morbidity? Trends in healthy-life expectancy in the elderly Austrian population between 1978 and 1998." Social Science and Medicine 52(3): 385-391.

Doblhammer, G., R. Rau, and J. Kytir. 2005. "Trends in educational and occupational differentials in all-cause mortality in Austria between 1981/82 and 1991/92." Wiener Klinische Wochenschrift 117(13-14): 468-479. 
European Commission. 2010. "Policy Needs for Better Life Expectancy Statistics." Document for the Working Group on Demography and Census, Luxembourg, 19-20 April 2010.

Holm, S. 1979. "A simple sequentially rejective multiple test procedure." Scandinavian Journal of Statistics 6(2): 65-70.

Idler, E. and J. Benyamini. 1997. "Self-rated health and mortality: a review of twentyseven community studies." Journal of Health and Social Behavior 38(1): 21-37.

Jagger, C., B. Cox, S. Le Roy, and the EHEMU team. 2001. "Health expectancy calculation by the Sullivan method: a practical guide." European concerted action on the harmonization of health expectancy calculations in Europe (EURO-REVES), REVES paper 408.

Jasilionis, D., V. Shkolnikov, E. Andreev, D. Jdanov, D. Ambrozaitiene, V. Stankuniene, F. Meslé, and J. Vallin. 2007. "Sociocultural mortality differentials in Lithuania: Results obtained by matching vital records with the 2001 census data." Population-E 62(4): 597-646.

Johnson, B. 2007. "Variations persist in life expectancy by social class." National Statistics News Release, 24 October 2007, accessed 28 May 2010 from «http://www.statistics.gov.uk/pdfdir/le1007.pdf».

KC, S., B. Barakat, A. Goujon, V. Skirbekk, W. Sanderson, and W. Lutz. 2010. "Projection of populations by level of educational attainment, age, and sex for 120 countries for 2005-2050." Demographic Research 22: 383-472.

Klimont, J. 2008. "Die Österreichische Gesundheitsbefragung 2006/2007: Ergebnisse zum Gesundheitszustand." Statistische Nachrichten 63(1): 30-40.

Klimont, J. and E. Urbas. 2002: "Fragen zur Gesundheit: Befindlichkeit, Beschwerden und Erkrankungen. Mikrozensus September 1999." Statistische Nachrichten 57(3): 147-158.

Klimont, J., P. Ihle, E. Baldaszti, and J. Kytir. 2008. Sozio-demographische und sozioökonomische Determinanten von Gesundheit. Auswertungen der Daten aus der Österreichischen Gesundheitsbefragung 2006/2007. Wien, Statistik Austria.

Klotz, J. 2007. "Soziale Unterschiede in der Sterblichkeit. Bildungsspezifische Sterbetafeln 2001/2002." Statistische Nachrichten 62(4): 296-311.

Klotz, J. and G. Doblhammer. 2008. "Trends in educational mortality differentials in Austria between 1981/82 and 2001/2002: A study based on a linkage of census data and death certificates." Demographic Research 19: 1759-1780.

Kohls, M. 2008a. "Healthy-Migrant-Effect, Erfassungsfehler und andere Schwierigkeiten bei der Analyse der Mortalität von Migranten. Eine Bestandsaufnahme." Working Paper 15, Nürnberg Forschungsgruppe des Bundesamtes für Migration und Flüchtlinge.

Kohls, M. 2008b. "Leben Migranten wirklich länger? Eine empirische Analyse der Mortalität von Migranten in Deutschland." Working Paper 16, Nürnberg Forschungsgruppe des Bundesamtes für Migration und Flüchtlinge.

Kunst, A. 1997. Cross-national comparisons of socio-economic differences in mortality. Department of Public Health, Rotterdam, Erasmus University.

Kuntsche, S. and G. Gmel. 2005. "The smoking epidemic in Switzerland - an empirical examination of the theory of diffusion of innovations." Sozial- und Präventivmedizin 50(6): 344-354. 
Laditka, S. and M. Hayward. 2003. "The evolution of demographic methods to calculate health expectancies." In: J. Robine et al. (eds.) Determining Health Expectancies. Chichester, Wiley, pp. 221-234.

Leclerc, A., J. Chastang, G. Menvielle, and D. Luce. 2006. "Socioeconomic inequalities in premature mortality in France: Have they widened in recent decades?" Social Science \& Medicine 62(8): 2035-2045.

Mackenbach, J. and A. Kunst. 1997. "Measuring the magnitude of socio-economic inequalities in health: An overview of available measures illustrated with two examples from Europe." Social Science \& Medicine 44(6): 757-771.

Mackenbach, J., W. Meerding, and A. Kunst. 2007. Economic implications of socioeconomic inequalities in health in the European Union. By order of the European Commission, Health and Consumer Protection Directorate-General, Luxembourg, OIL.

Martikainen, P., J. Blomgren, and T. Valkonen. 2007. "Change in the total and independent effects of education and occupational social class on mortality: analyses of all Finnish men and women in the period 1971-2000." Journal of Epiodemiology and Community Health 61(6): 499-505.

Mitterndorfer, B. 2008. “Daten des Mikrozensus ab 1974.” Statistische Nachrichten 63(9): 804-815.

Molla, M., J. Madans, and D. Wagener. 2004. "Differentials in adult mortality and activity limitation by years of education in the United States at the end of the 1990s." Population and Development Review 30(4): 625-646.

Nusselder, W. 2003. "Compression of morbidity." In: J. Robine et al. (eds.) Determining Health Expectancies. Chichester, Wiley, pp.35-58.

Pamuk, E. 1985. "Social class inequality in mortality from 1921 to 1972 in England and Wales." Population Studies 39(1): 17-31.

Perenboom, R., L. Van Herten, H. Boshuizen, and G. Van Den Bos. 2005. "Life expectancy without chronic morbidity: trends in gender and socioeconomic disparities." Public Health Reports 120(1): 46-54.

Pettersson, H. 1995. "Trends in health expectancy for socio-economic groups in Sweden." REVES paper 214, presented at the 8th REVES work-group meeting, Chicago.

Schneider, S. 2008. "Der Schichtgradient von Morbidität und Mortalität." Österreichische Zeitschrift für Soziologie 33(1): 43-66.

Schwabe, M. 2005. "Erstellung des Bildungsstandregisters: Neu-Imputation der fehlenden Bildungsabschlüsse des Volkszählungsbestands 2001." Arbeitsbericht, Wien, Statistik Austria.

Shkolnikov, V., E. Andreev, D. Jasilionis, M. Leinsalu, O. Antonova, and M. McKee. 2006. "The changing relation between education and life expectancy in central and eastern Europe in the 1990s." Journal of Epidemiology and Community Health 60(10): 875-881.

Shkolnikov, V., E. Andreev, D. Jdanov, D. Jasilionis, and T. Valkonen. 2009. "To what extent do rising mortality inequalities by education and marital status attenuate the general mortality decline? The case of Finland in 1971-2030." Working Paper 2009-018. Rostock, Max Planck Institute for Demographic Research.

Spoerri, A., M. Zwahlen, M. Egger, F. Gutzwiller, C. Minder, and M. Bopp. 2006. "Educational inequalities in life expectancy in the German speaking part of Switzerland between 1990 and 1997: Swiss National Cohort." Swiss Medical Weekly 136(09): 145-148. 
Urbas, E. and J. Klimont. 2002. Rauchgewohnheite-Ergebnisse des Mikrozensus Dezember 1997. Wien, Statistik Austria.

Valkonen, T. 2001. "Trends in differential mortality in European countries". In: J. Vallin et al. Trends in mortality and differential mortality. Populations studies No. 36, Strasbourg, Council of Europe Publishing.

Vallin, J. and F. Meslé. 2004. "Convergences and divergences in mortality. A new approach to health transition." Demographic Research Special Collection 2: 11-44. 


\section{Appendix}

Table A.1:

Survey Characteristics

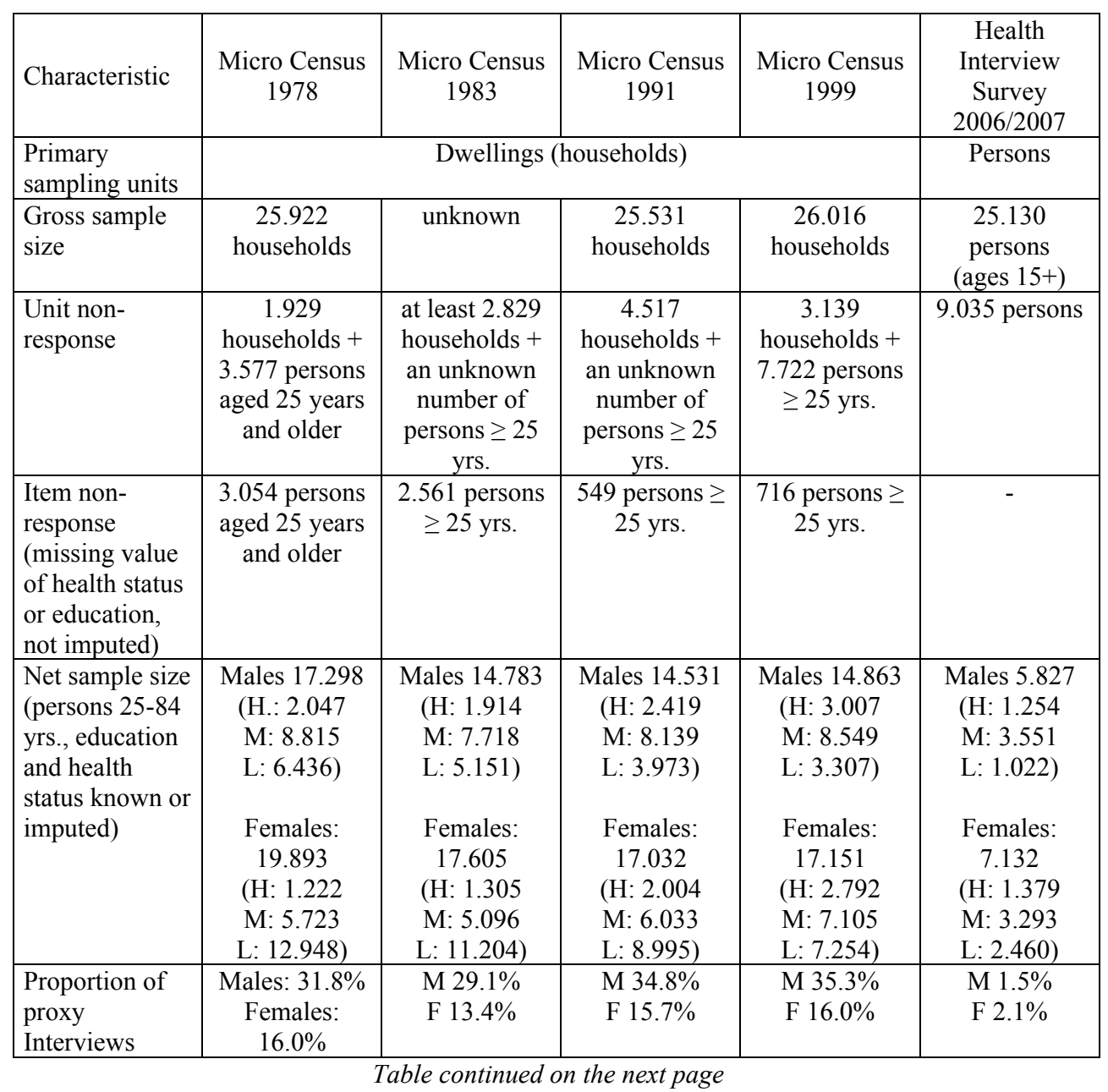


Table A.1 (continued)

\begin{tabular}{|c|c|c|c|c|c|}
\hline $\begin{array}{l}\text { Estimated } \\
\text { overall design } \\
\text { effects }\end{array}$ & $\begin{array}{c}\text { Males: } 1.78 \\
\text { Females: } 1.73\end{array}$ & $\begin{array}{l}\text { M } 1.82 \\
\text { F } 1.72\end{array}$ & $\begin{array}{l}\text { M } 1.72 \\
\text { F } 1.69\end{array}$ & $\begin{array}{l}\text { F } 1.40 \\
\text { F } 1.35\end{array}$ & $\begin{array}{l}\text { M } 1.48 \\
\text { F } 1.53\end{array}$ \\
\hline $\begin{array}{l}\text { Effective net } \\
\text { sample size } \\
\text { (persons 25-84 } \\
\text { yrs., education } \\
\text { known or } \\
\text { imputed) }\end{array}$ & $\begin{array}{c}\text { Males } 9.700 \\
\text { Females } \\
11.500\end{array}$ & $\begin{array}{l}\text { M } 8.100 \\
\text { F } 10.200\end{array}$ & $\begin{array}{l}\text { M } 8.400 \\
\text { F } 10.100\end{array}$ & $\begin{array}{l}\text { M } 10.600 \\
\text { F } 12.700\end{array}$ & $\begin{array}{l}\text { M } 3.900 \\
\text { F } 4.700\end{array}$ \\
\hline $\begin{array}{l}\text { Question } \\
\text { wording on } \\
\text { self-perceived } \\
\text { health status } \\
\text { (German) }\end{array}$ & \multicolumn{4}{|c|}{ "Wie beurteilen Sie im Allgemeinen Ihren Gesundheitszustand?" } & $\begin{array}{l}\text { "Wie ist Ihre } \\
\text { Gesundheit im } \\
\text { Allgemeinen?" }\end{array}$ \\
\hline $\begin{array}{l}\text { Answer } \\
\text { wording } \\
\text { (German) }\end{array}$ & \multicolumn{5}{|c|}{ "sehr gut - gut - mittelmäßig - schlecht - sehr schlecht" } \\
\hline
\end{tabular}

Notes: In the HIS 2006 proxy interviews were allowed only if the respondent was for health reasons unable to answer. Education-specific design effects are usually close to the overall design effects.

Source: Statistics Austria

Table A.2:

Population in institutions among the elderly Austrian population

\begin{tabular}{|c|c|c|c|c|c|c|c|c|}
\hline \multirow{3}{*}{ Census } & \multicolumn{8}{|c|}{ Institutionalised population per 100 total population } \\
\hline & \multicolumn{4}{|c|}{ Males by age group } & \multicolumn{4}{|c|}{ Females by age group } \\
\hline & $65-69$ & $70-74$ & $75-79$ & $80-84$ & $65-69$ & $70-74$ & $75-79$ & $80-84$ \\
\hline 1981 & 1.2 & 1.8 & 2.8 & 5.0 & 1.8 & 2.8 & 5.2 & 9.8 \\
\hline 1991 & 1.0 & 1.3 & 2.5 & 4.3 & 1.2 & 2.1 & 4.5 & 8.7 \\
\hline 2001 & 0.9 & 1.1 & 2.0 & 3.8 & 1.1 & 1.8 & 3.7 & 8.1 \\
\hline 2006 & 0.9 & 1.2 & 1.8 & 3.7 & 1.0 & 1.7 & 3.3 & 7.9 \\
\hline \multicolumn{9}{|c|}{2001 by educational level } \\
\hline High & 1.2 & 1.2 & 1.6 & 3.8 & 1.4 & 1.7 & 3.2 & 6.6 \\
\hline Medium & 0.5 & 0.7 & 1.4 & 2.9 & 1.1 & 1.7 & 3.4 & 7.9 \\
\hline Low & 1.4 & 1.7 & 2.8 & 4.6 & 1.0 & 1.8 & 3.9 & 8.3 \\
\hline
\end{tabular}

Note: At the 2001 census the institutionalised population aged 65-84 was distributed by type of institution as follows: $70 \%$ old-age homes, $19 \%$ disability and nursing homes, $11 \%$ other types of institutions. 2006 refers to the register based census test (no official Austrian census).

Source: Statistics Austria 
Table A.3:

Age-specific proportion (\%) of the population in self-perceived (very) good health, Austria 1981 vs. 2006

\begin{tabular}{|c|c|c|c|c|c|c|c|c|}
\hline \multirow{3}{*}{$\begin{array}{l}\text { Age } \\
\text { group }\end{array}$} & \multicolumn{4}{|c|}{ Males } & \multicolumn{4}{|c|}{ Females } \\
\hline & \multirow{2}{*}{ Total } & \multicolumn{3}{|c|}{ by educational level } & \multirow{2}{*}{ Total } & \multicolumn{3}{|c|}{ by educational level } \\
\hline & & High & Medium & Low & & High & Medium & Low \\
\hline \multicolumn{9}{|l|}{1981} \\
\hline 25-29 & 91 & 94 & 91 & 90 & 88 & 91 & 91 & 83 \\
\hline $30-34$ & 90 & 96 & 89 & 87 & 88 & 93 & 90 & 84 \\
\hline $35-39$ & 86 & 92 & 85 & 85 & 82 & 93 & 85 & 76 \\
\hline $40-44$ & 78 & 86 & 79 & 72 & 75 & 88 & 81 & 70 \\
\hline $45-49$ & 70 & 87 & 71 & 63 & 66 & 77 & 72 & 62 \\
\hline $50-54$ & 61 & 80 & 62 & 51 & 57 & 74 & 64 & 51 \\
\hline $55-59$ & 52 & 78 & 51 & 44 & 49 & 65 & 52 & 46 \\
\hline $60-64$ & 49 & 65 & 52 & 38 & 43 & 59 & 55 & 37 \\
\hline $65-69$ & 45 & 70 & 46 & 35 & 34 & 53 & 37 & 31 \\
\hline $70-74$ & 36 & 54 & 39 & 28 & 30 & 44 & 41 & 26 \\
\hline $75-79$ & 29 & 42 & 32 & 22 & 22 & 41 & 27 & 20 \\
\hline 80-84 & 24 & 37 & 27 & 17 & 15 & 33 & 17 & 14 \\
\hline \multicolumn{9}{|l|}{2006} \\
\hline 25-29 & 95 & 97 & 94 & 90 & 91 & 96 & 88 & 86 \\
\hline $30-34$ & 90 & 95 & 89 & 78 & 90 & 95 & 91 & 80 \\
\hline $35-39$ & 90 & 96 & 88 & 91 & 87 & 90 & 88 & 77 \\
\hline $40-44$ & 86 & 95 & 84 & 73 & 85 & 91 & 87 & 71 \\
\hline $45-49$ & 78 & 86 & 74 & 81 & 80 & 91 & 82 & 61 \\
\hline $50-54$ & 72 & 82 & 72 & 55 & 67 & 86 & 69 & 53 \\
\hline $55-59$ & 57 & 79 & 55 & 34 & 64 & 82 & 65 & 52 \\
\hline $60-64$ & 60 & 73 & 59 & 49 & 70 & 78 & 73 & 63 \\
\hline $65-69$ & 62 & 82 & 61 & 51 & 58 & 62 & 67 & 49 \\
\hline $70-74$ & 50 & 70 & 50 & 39 & 46 & 56 & 62 & 34 \\
\hline $75-79$ & 46 & 59 & 48 & 37 & 41 & 58 & 48 & 34 \\
\hline 80-84 & 39 & 46 & 42 & 29 & 29 & 26 & 33 & 28 \\
\hline \multicolumn{9}{|c|}{ Change 2006-1981 } \\
\hline 25-29 & 3 & 3 & 3 & 0 & 3 & 5 & -3 & 3 \\
\hline $30-34$ & 0 & -2 & 0 & -9 & 2 & 2 & 0 & -4 \\
\hline $35-39$ & 4 & 4 & 3 & 6 & 5 & -3 & 2 & 1 \\
\hline $40-44$ & 8 & 8 & 6 & 1 & 10 & 3 & 7 & 1 \\
\hline $45-49$ & 8 & -1 & 2 & 18 & 14 & 14 & 10 & -1 \\
\hline $50-54$ & 12 & 2 & 10 & 4 & 11 & 12 & 4 & 2 \\
\hline $55-59$ & 5 & 1 & 4 & -10 & 14 & 18 & 13 & 5 \\
\hline $60-64$ & 11 & 8 & 7 & 11 & 27 & 19 & 17 & 26 \\
\hline $65-69$ & 17 & 12 & 16 & 16 & 25 & 9 & 30 & 18 \\
\hline $70-74$ & 14 & 15 & 11 & 11 & 16 & 12 & 21 & 8 \\
\hline $75-79$ & 16 & 17 & 16 & 15 & 18 & 17 & 21 & 15 \\
\hline $80-84$ & 15 & 9 & 15 & 12 & 14 & -7 & 16 & 14 \\
\hline
\end{tabular}

Note: The 1981 estimates are simple averages of the 1978 and 1983 estimates Source: Statistics Austria 


\section{Variance estimation for life expectancy}

Consider a life table starting at the $25^{\text {th }}$ birthday, so $l_{25}=1$. Let $l_{x}$ denote the survival probability to the $x^{\text {th }}$ birthday, $e_{x}$ the remaining life expectancy at the $x^{\text {th }}$ birthday and $q_{x}$ the one-year conditional probability of dying between the $x^{\text {th }}$ and the $(x+1)^{\text {th }}$ birthday, given a person has survived to the $x^{\text {th }}$ birthday.

Then the variance of $q_{x}$ equals $\operatorname{Var}\left(q_{x}\right)=\frac{q_{x}^{2}\left(1-q_{x}\right)}{D_{x}}$, with $D_{x}$ the observed number of deaths at age $[x, x+1)$ during the observation period. (Hint: In the denominator we inserted the matched number of deaths, which is typically lower than the actual number of deaths, so our calculations can be seen as conservative approximations.)

By Taylor series expansion we can now combine those variances of one-year age-specific probabilities of dying to approximate the variance of life expectancy:

$\operatorname{Var}\left(e_{25}\right)=\sum_{x=25}^{\omega-1}\left(l_{x}^{2} * \operatorname{Var}\left(q_{x}\right) *\left(e_{x+1}+0.5\right)^{2}\right)$,

where $\omega$ denotes the upper age limit of the life table, in our case 95 years. For partial life expectancy at ages 25-84 the same formula is used, but with $\omega=85$. A detailed derivation of the formulae is given by Chiang (1984: ch. 8).

\section{Calculation of partial health expectancy}

Denote by $y$ the 5 -year age group $[x, x+5)$. For each age group we estimate from a sample survey the proportion $\pi_{y}$ of the population in self-perceived (very) good health ( $\pi_{y}$ is 0 if no survey respondent in the respective age group self-rates its health as (very) good, and 1 if all survey respondents in the respective age group self-rate their health as (very) good). Health expectancy at ages $25-84$ is then calculated by the Sullivan method as

$$
h_{[25,85)}=\sum_{y=[25,30)}^{[80,85)} \pi_{y} L_{y},
$$

where $L_{y}$ denotes the life-table population (person-years lived) in the respective 5-year age group.

\section{Estimation of design effects}

The design effect is defined as the ratio of the actual variance of a linear statistic (e.g. a proportion) in the realised sample to its theoretical variance in a model 
simple random sample. In our case it can be estimated as follows. The agespecific proportion of the population in self-perceived (very) good health may be written as a weighted mean, $\pi_{y}=\frac{\sum_{j} z_{j} w_{j}}{\sum_{j} w_{j}}$, where $j$ is an index for the survey respondents in age group $y, w_{j}$ is the sample weight of the $j$ 'th respondent and $z_{j}$ is a dichotomous variable which is 1 if this respondent self-rates its health as (very) good and 0 otherwise. Sample weights essentially account for regional stratification and primary sampling unit non response and were calibrated independently of the $z_{j}$ 's. In this case the design effect $\Delta_{y}$ approximates

$$
\Delta_{y}=1+\left[c v\left(w_{y}\right)\right]^{2},
$$

where $c v\left(w_{y}\right)$ denotes the coefficient of variation of the sample weights in the age group of interest. If at least two weights are unequal, then $\Delta_{y}>1$, meaning that the variance of $\pi_{y}$ estimate is greater than if it were obtained from a model simple random sample. It turned out that estimated design effects and average weights did not vary a lot by age group, so for each population of interest we used an average design effect $\bar{\Delta}$ for all age groups.

\section{Variance estimation for partial health expectancy}

The variance of the age-specific proportion of the population in self-rated very good or good health equals $\operatorname{Var}\left(\pi_{y}\right)=\frac{\pi_{y}\left(1-\pi_{y}\right) \bar{\Delta}}{n_{y}}$, with $n_{y}$ the age-specific number of survey respondents. As health estimates are available for 5-year age groups, we also have to combine one-year probabilities of dying into 5-year probabilities of dying: $q_{y}=1-\prod_{i=x}^{x+4}\left(1-q_{i}\right)$. By Taylor series expansion one can

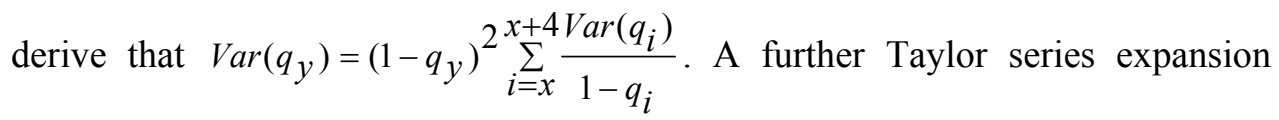
gives the approximate variance of partial health expectancy:

$\operatorname{Var}\left(h_{[25,85)}\right)=\sum_{y=[25,30)}^{[80,85)}\left[l_{x}^{2} *\left(5 *\left(1-f_{y}\right) * \pi_{y}+h_{[x+5,85)}\right)^{2} * \operatorname{Var}\left(q_{y}\right)+L_{y}^{2} * \operatorname{Var}\left(\pi_{y}\right)\right]$ where $f_{y}$ denotes the life table fraction of the interval $y$ lived by those who die in $y$ (which is typically close to 0.5 ) and $x$ denotes the lower endpoint of the interval $y$. The formula above - slightly modified - was taken from Davis et al. (1999). 


\section{Test statistic for significance tests}

In Table 3 we indicate whether educational differences were significantly different in 2006 from in 1981. The test statistic for those significance tests is derived as follows. Let us denote by $e_{A}\left(t_{1}\right)$ and $e_{B}\left(t_{1}\right)$ the health outcomes (e.g. life expectancies) of educational groups $A$ and $B$ in 1981. The corresponding educational difference in 1981 is thus denoted by $e_{A}\left(t_{1}\right)-e_{B}\left(t_{1}\right)$. Accordingly let us denote the educational difference in 2006 by $e_{A}\left(t_{2}\right)-e_{B}\left(t_{2}\right)$. Then the change in that educational difference in 1981-2006 is ${ }^{c} A, B=\left[e_{A}\left(t_{2}\right)-e_{B}\left(t_{2}\right)\right]-\left[e_{A}\left(t_{1}\right)-e_{B}\left(t_{1}\right)\right]$ and since the outcomes for $A$ and $B$ as well as for $t_{1}$ and $t_{2}$ are stochastically independent its variance is $\operatorname{Var}\left(c_{A, B}\right)=\operatorname{Var}\left(e_{A}\left(t_{2}\right)\right)+\operatorname{Var}\left(e_{B}\left(t_{2}\right)\right)+\operatorname{Var}\left(e_{A}\left(t_{1}\right)\right)+\operatorname{Var}\left(e_{B}\left(t_{1}\right)\right) . \quad$ The test statistic is then computed in the usual way as $\widetilde{z}_{A, B}=c_{A, B} / \sqrt{\operatorname{Var}\left(c_{A, B}\right)}$.

\section{Multiple significance tests: Holm's procedure}

For any combination of sex and measure we compare three changes in educational differences (High vs. Medium, Medium vs. Low, High vs. Low) and so obtain three test statistics: $\widetilde{z}_{1}, \widetilde{z}_{2}, \widetilde{z}_{3}$. For each $\widetilde{z}$, we denote by $p$ the probability that in absolute value a standard Normal random variable is greater than $\widetilde{z}$. We sort the three $p$-values in ascending order, i.e. $p^{(1)} \leq p^{(2)} \leq p^{(3)}$. Holm's multiple test procedure is now as follows:

1. If $p^{(1)} \geq 0.05 / 3$, then all three changes in educational differences are considered non-significant and the procedure is done. If $p^{(1)}<0.05 / 3$, then the corresponding change is considered statistically significant and the procedure is continued.

2. If $p^{(2)} \geq 0.05 / 2$, then the remaining two changes are considered nonsignificant and the procedure is done. If $p^{(2)}<0.05 / 2$, then the corresponding change is considered statistically significant and the procedure is continued.

3. If $p^{(3)} \geq 0.05$, then the remaining change is considered non-significant. If $p^{(3)}<0.05$, then also this change is considered statistically significant.

Holm's procedure is applicable to any multiple tests and keeps the family-wise error rate, i.e. the probability of rejecting at least one true null hypothesis, at the 0.05 level (Holm 1979). 